\title{
El legado de Marta Traba: Reflexiones teóricas en torno a la creación artística en América Latina 1983-2003
}

Angie Gloriela Montiel Muñoz

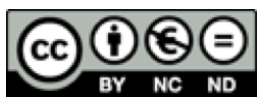

Esta obra está bajo una licencia Creative Commons

Reconocimiento-No comercial-Sin Obra Derivada 



\title{
El legado de Marta Traba: Reflexiones teóricas en torno a la creación artística en América Latina 1983-20031
}

\author{
Angie Gloriela Montiel Muñoz \\ Programa de Posgrado en Artes Visuales. Universidade Federal da Bahia, UFBA-Brasil \\ yimonti@gmail.com
}

Recibido: 01 de mayo de 2016 Aprobado: 20 de octubre de 2016

\section{Resumen}

El 27 de noviembre de 1983, los ojos sagaces e impetuosos de una de las críticas y teóricas más importantes del arte en América Latina se cerraron repentinamente; sin embargo, sus ideas continúan latentes con un poder tal vez aún mayor para explicar dialécticamente las dinámicas del arte como parte de la sociedad. Es esta perspectiva la que guía el presente artículo, al exponer una relectura de la obra de Marta Traba y la vigencia de su pensamiento, propuesta que parte del abordaje de cuatro ejes fundamentales de su teoría: la estética del deterioro, la cultura de la resistencia, las dinámicas de centro-periferia y las categorías de áreas abiertas y áreas cerradas. Este abordaje analítico y sistemático es acompañado de una serie de reflexiones teóricas respecto a la creación artística en América Latina, entre los años 1983-2003.

Palabras clave: Marta Traba, Teoría del arte, Crítica del arte, estética del deterioro, cultura de la resistencia, América Latina.

\begin{abstract}
On November 27, 1983, one of the most important art critic and theorist in Latin America closed her sagacious and impetuous eyes suddenly. Nevertheless, her ideas remain dormant with perhaps even greater power to explain a dialectical way the art as part of society. This perspective guides this article

${ }^{1}$ Este artículo fue presentado originalmente como ponencia en el XXX Congreso de la Asociación Latinoamericana de Sociología (ALAS) del 2015, llevado a cabo en Costa Rica.
\end{abstract}




\section{Artículos}

by exposing a rereading of the work of Marta Traba and the validity of her thoughts from the analysis of four conceptual categories of her theory: estética del deterioro, cultura de la resistencia, the dynamics of center-periphery and the categories namely open areas and closed areas. This analytical and systematic approach is accompanied by a series of theoretical reflections on artistic creation in Latin America between the years 1983 and 2003.

Keywords: Marta Traba, Theory of art, Art Criticism, aesthetic of deterioration, culture of resistance, Latin America. 


\section{La palabra audaz}

Amada y odiada por su suspicacia, inteligencia, militancia y dominio de la palabra; entre crítica, teoría y polémica, Marta Traba desarrolla su papel de intelectual en el continente americano, ejerciendo de forma apasionada, por más de 30 años, su trabajo de crítica, análisis e investigación en torno a la creación artística de su época, marcando profundamente el arte en América Latina. Su intensa labor en el medio colombiano durante los años cincuenta y su efervescente actuación por todo el continente durante la década de los sesenta e inicios de los setenta, le brindaron la experiencia lucidez y criterio para llegar -según nuestra perspectiva- al clímax de su postura teórica.

Este artículo aborda precisamente el trabajo teórico desarrollado durante este periodo de clímax de la década del 70, en el cual Traba publicó la mayoría de libros y artículos que son citados más adelante. El marco conceptual desarrollado por esta autora durante este periodo presenta una característica que no está del todo ausente en sus trabajos anteriores, sin embargo, es más evidente en estos años. Nos referimos al método dialéctico, el cual impide que este corpus teórico perezca en la ontología del arte al que la historiografía clásica había condicionado su estudio, permitiendo integrar esta esfera de lo social a la totalidad, sirviéndose de otras disciplinas y epistemologías para explicar los fenómenos del arte.

Es esta perspectiva dialéctica la que le da a la palabra de Traba -a su legado- la importancia de una propuesta teórica móvil, navegante en las aguas de la historia, que si bien debe ser criticada, permite estudiar las dinámicas del arte de forma amplia y profunda, más allá del campo de la estética, promoviendo un estudio crítico sobre el momento histórico del que el arte es partícipe, articulando en este movimiento a artistas-sujetos histórico-sociales-y público.

Gracias a esta perspectiva analítica -arte sociedad/parte-totalidad- la teoría de Marta Traba continua vigente. En este artículo se expone esa vigencia mediante una relectura de su teoría a través de cuatro ejes, el primero es la estética del deterioro, postura que brinda la posibilidad de analizar el fenómeno de la posmodernidad, abordaje realizado a partir de reflexiones sobre la obra de Fredric Jameson, Postmodernism, or, the cultural logic of late capitalism (1992).

Esta reflexión conduce al siguiente eje: la cultura de la resistencia, tesis que permite el análisis de una serie de factores que intervienen en la creación artística, entre los cuales se destacan la cuestión de la identidad expuesta a través de la perspectiva de Traba y de los estudios de Gerardo Mosquera, Del arte Latinoamericano al arte desde América Latina (2003), y de María Laura Ise, Arte Latinoamericano en los ochenta y noventa: Una mirada desde algunas exibiciones y catálogos (2011).

El tercer eje a abordar es la dinámica de centro-periferia, que remite al estudio sobre los centros hegemónicos y su paradoja agridulce de reproducción ideológica y 


\section{Artículos}

homogeneizante. La reflexión de este eje se enriquece con la perspectiva de Roberto Ayala (2004) y Bolívar Echeverría (2011) en materia de economía política, y con el estudio de Nelly Richard (1997) que amplía este abordaje, advirtiendo sobre las injerencias de estas dimensiones sociales en el campo académico de América Latina.

El último eje a tratar es el de áreas abiertas y áreas cerradas, enfocadas en el caso de Venezuela y Centroamérica, y el periodo de la década del ochenta y noventa. En el análisis sobre el caso venezolano se desarrolla, en el texto, un diálogo con cuatro autoras: Ruth Auerbach (1997), Jenny Guerrero (2009), Nidia Tabarez (2009) y Esther Morales (2009), quienes analizan la historia y el desenvolvimiento del arte venezolano desde diversas perspectivas que aportan aspectos valiosos al enfoque y reflexión de la teoría de Traba.

Pablo Hernández y Virginia Pérez Ratton son los autores abordados para tratar el arte centroamericano. A partir del estudio de Hernández, Hacer cosas con palabras y con imágenes. La dimensión performativa del arte en Centroamérica (2015) y los apuntes crítico-reflexivos de Pérez Ratton (2011), quien fuera una de las más importantes promotoras del arte contemporáneo centroamericano, se analiza la dinámica del arte durante el periodo convulsionado de la transición a la paz en esta región.

En el marco de esta propuesta, se toma también en consideración la repercusión de dos eventos de profunda envergadura a nivel mundial: la caída del Muro de Berlín y la caída de las Torres Gemelas, realizando, a través de breves -y esperamos provocadoras- reflexiones su abordaje que, si bien nuestro aporte es sólo una pincelada de los acontecimientos y fenómenos de una época, funciona como una muestra para develar las posibilidades analíticas que el trabajo de Traba brinda al estudio de los procesos artísticos, particularmente en América Latina, con el objetivo de abrir portillos para futuras investigaciones que permitan abordar el arte de forma totalizadora, contrario al dogma de pensarlo como una esfera hedonista, ajena a la sociedad.

\section{Estética del deterioro; Sobre alas fugaces}

Novedoso, libre, efímero; estos son algunos de los adjetivos que caracterizan el primer eje teórico a abordar, que pese a sus rasgos particularmente seductores Traba no dudo en nombrarla como estética del deterioro, que, como se expone a continuación, la fundamentación de este concepto parte de otros elementos, además del juicio estético y formal.

Entre las décadas de 1950 y 1970 se generó entre los intelectuales un interés particular -propiciado por el momento histórico y de cambio en la corriente moderna - por investigar e analizar las nuevas dinámicas emergidas entre los centros hegemónicos y las periferias. Marta Traba no fue indiferente ante estas investigaciones; por el contrario, su pensamiento fue enriquecido por posturas como la Teoría de la Dependencia y la Teoría Crítica. 
En los años setenta, las investigaciones de Traba se centraron en Estados Unidos y América Latina, enfocándose en la actividad artística, pero a través de una perspectiva que la integra a la sociedad; lo anterior le permitió entrever las relaciones entre las vanguardias artísticas norteamericanas y la sociedad de consumo, determinando que ambas fortalecían, a lo que ella llamo tecnología ideológica (Traba, 2005, p. 60). Para Traba, esta ideología opera de forma alienante a través de una falsa libertad que sustituye la creatividad por la producción de formas prefabricadas, remplazando la estética tradicional -lo existente y perdurable- por la estética del deterioro ${ }^{2}$, la cual satisface de forma ilusoria y efímera.

De esta forma, la estética del deterioro es, al mismo tiempo, ecuación y resultado de un proceso de alienación de los sujetos sociales, quienes consumen ideológica y materialmente los productos del arte fascinados con la promesa del deleite entretejido en la diversión y liberación de nunca acabar, ya que, sin problema, estos productos son reemplazados como cualquier otra mercancía de la industria cultural ${ }^{3}$.

El lenguaje juega también un papel importante en ese proceso, analizado por Traba a través del concepto de código general de Henri Lefebvre, que remite a un "[...] sistema global emanado por la sociedad para establecer signos y significados también generales cuya compresión consolide la armonía del hombre con su comunidad" (Traba, 2005, p. 59).

Para Traba, este código ha sido remplazado por señales ruta que funcionan como "[...] un indicador mecánico, pauperizado, capacitado para marcar un camino a seguir pero impotente para abrir el complejo meollo de una estructura de sentido como lo es el lenguaje." (Traba, 2005, p. 64).

En el artículo "La pintura como medio de comunicación" (1973), Marta Traba aborda el lenguaje desde el concepto de mensaje poético, el cual es propio de la creación artística al representar múltiples significados a través de su capacidad simbólica. Esta capacidad ha sido reemplazada por los metalenguajes, formas incomprensibles volcadas a ser señales ruta. El Pop, el Kisch y el Camp son los productos artísticos del american way of art que funcionan como fuentes de señales ruta, expandiendo sistemas de vida condicionados a la sociedad de consumo, que resulta en lo que Traba llamo el éxito de los derrotados (Traba, 1970).

\footnotetext{
${ }^{2}$ Este concepto fue empleado inicialmente por Traba en 1964 para referirse al fenómeno efervescente de las vanguardias en los circuitos europeos y norteamericanos. Un año después, la autora lo amplió hacia las características expuestas en este artículo (Traba, 2005, p. 60).

${ }^{3}$ Theodor W. Adorno y Max Horkheimer son los autores de este concepto y forman parte del grupo de intelectuales de la Teoría crítica. Como se menciona en el texto, Traba enriqueció sus investigaciones con estos estudios.
} 


\section{Artículos}

La estética del deterioro guarda una estrecha relación con lo que diversos autores han designado como posmodernismo. Traba no se refirió mucho a este concepto, sin embargo, sus categorías son herramientas de estudio que posibilitan abordar ese fenómeno en América Latina.

Por ejemplo, en estudios posteriores tal como Postmodernism, or, the cultural logic of late capitalism (1992) del teórico norteamericano Fredric Jameson, se abordan aspectos tales como las formas culturales de dominación norteamericana a nivel mundial, las cuales obedecen a la lógica del capital, en la que categorías abordadas por Traba como la tecnología ideológica, la sociedad de consumo y la industria cultural, son también de importancia en el estudio de Jameson.

En esta dinámica, el arte convertido en producto pierde lo que Jameson (1992, p. 16) llama -su distintiva y propia pinceladapara convertirse en una parodia, una imitación - un pastiche- que reproduce señales ruta, que se pueden entrever en la década de los ochenta en los Estados Unidos, década impregnada por una nostalgia de los años 50 y 60 utilizada para transformar el pasado en una estereotipada tarjeta postal (Jameson, 1992, p. 296).

La creación de este pasado en una gloriosa ilusión enriquece la ideología alienante; digerido y amado por la cultura de masas, el arte es despojado del acto crítico para ser utilizado y desechado por la dinámica posmoderna.

\section{La cultura de la resistencia; Tenacidad para significar}

Ante la estética del deterioro, Traba plantea una categoría antagónica -sin embargo, dialéctica-, impulsada por la necesidad de comprender el mundo circundante y valerse de todas sus partes para llevar a cabo el acto creativo. Esta es la cultura de la resistencia, tesis que tiene su origen en el análisis sobre la postura de algunos de los artistas latinoamericanos ante las vanguardias internacionales, actitud que, para Traba, es revolucionaria.

En el artículo "La cultura de la resistencia" (2009) Traba coloca a la categoría de dependencia en una posición dinámica entre motivante-castrante sobre los trabajos emprendidos por los intelectuales y artistas en América Latina, no solo para los que se enfrentaban a la estética del deterioro de los sesentas, sino también para quienes décadas antes se opusieron a las formas de dominación de manera inteligente y genuina.

La resistencia surge en el momento en que la cultura dominada se vale de su dominación para crear formas de comprensión sobre su historia. Esta es, para Traba su mayor potencialidad, al brindar la posibilidad de revelar a los grupos sociales las dinámicas ocultas de la sociedad, abriendo el velo de la apariencia para entender sus realidades, proyectando la cultura de la resistencia no sólo como postura estética, sino como una epistemología (Traba, 2009, p. 142).

Para el artista, una cultura de resistencia representa la fuerza y tenacidad de significar, 
sirviéndose de los medios de expresión y comunicación que estén a su disposición para decir algo que pertenezca a un código general. En este punto, Traba se posiciona sobre la capacidad que los artistas latinoamericanos tienen para crear un arte propio, capaz de representar y expresar su realidad y su tiempo sin dejar de lado las especificidades y los valores regionales, al formar y enriquecer una estructura de sentido (Traba, 2005, p. 139).

La identidad y lo nacional son nociones recurrentes en el pensamiento de América Latina. Como formas fantasmales se presentan creando pánico y polémica. La teoría de Traba no escapa de esta escena y, frente a la radicalidad latinoamericanista que señalan otros autores en su pensamiento, existe una posición crítica ante ambos conceptos, articulando el primero como la llaga constante de afirmación y negación de nativismos e indigenismos $\mathrm{y}$, el segundo, como propenso a caer en un totalitarismo patriótico o en una bandera política panfletaria, el cual interfiere en el mensaje poético y juicio estético del arte $^{4}$.

Ambos elementos continúan en las décadas siguientes generando polémica sobre la creación artística en América Latina, por ejemplo, Gerardo Mosquera en su artículo "Del arte Latinoamericano al arte desde América Latina" (2003) analiza la identidad en torno a la categoría de latinoamericano, que actúa como cliché posmoderno homogeneizante al etiquetar el arte de la región y ocasiona una neurosis que conlleva, en muchos casos, a una idealización sobre los valores de lo nacional. Como enfatiza Mosquera (2003, p. 74) la identidad y la sociedad cambian, y ese cambio merece ser representado, no solo con elementos identitarios sino con la forma misma de hacer arte, volviendo, en este punto, a la originalidad y a la búsqueda de significar.

María Laura Ise (2011) analiza también la problemática de la representación de lo latinoamericano a través del interés que ha surgido de ciertos grupos de la crítica del arte en revalorar y re-articular las representaciones monolíticas, historicistas y reduccionistas de lo latinoamericano. Lecturas que han sido creadas e impuestas por los centros hegemónicos, las cuales no solo crean una visión ficticia de la región, sino que también despojan al arte de su reflexión teórica, sobreponiendo un espejismo atractivo para el mercado del arte.

En este sentido, podemos valorar la dicotomía que expresa Traba entre artistas "resistentes" y artistas "inventores" (2005, p. 109). Los primeros procuran significar en la diversidad, los segundos manipulan en el juego del deterioro un valor genérico, es decir, la necesidad de revalorar lo latinoamericano es resistencia y la dominación de los centros

\footnotetext{
${ }^{4}$ Traba analiza lo nacional y la identidad en su artículo "Artes plásticas latinoamericanas: La tradición de lo nacional" (1979). Aquí, aborda posturas de varios teóricos en torno a ambos conceptos en América Latina.
} 


\section{Artículos}

hegemónicos sobre la región -invención- es hacer de la periferia un producto.

\section{Dinámicas de centro-periferia; La paradoja del juego}

En América Latina la categoría de dependen$\mathrm{cia}^{5}$ abrió las puertas para analizar la condición de subordinación de los estados-nación de la región ante los centros hegemónicos, condición heredada de la colonia y que pasó a ser un factor constante en la estructura social. Esta categoría, como herramienta de análisis, está presente en las investigaciones de Marta Traba, tal como lo vemos en uno de sus libros más importantes Dos décadas vulnerables en las artes plásticas latinoamericanas, 1950-1970 (2005) en el cual analiza el arte en relación con las dinámicas económico-políticas de la región, vinculadas a los Estados Unidos.

Asimismo, en su obra Arte de América Latina: 1900-1980 (1994), está presente la noción de dinámica centro-periferia, un juego paradójico entre la hegemonía cultural de los circuitos del arte por parte de Europa y Estados Unidos, amparados en la ideología civilizatoria - como deseo frustrado de la vieja colonia- entrelazado a los fantasmas de búsqueda, falta o ausencia de identidad. Esta hegemonía cultural estudiada por Traba durante las décadas del sesenta y setenta, muestra una continuidad asociada a las décadas siguientes; es decir, no se da una transformación que afecte a los centros, por el contrario, parece que estos se consolidan durante las décadas ochenta y noventa, marcando, de forma particular, las relaciones de centro-periferia.

Ambas décadas estuvieron marcadas por diversos acontecimientos. Uno de los más emblemáticos, a nivel internacional, fue la caída del Muro de Berlín que, en palabras de Bolívar Echeverría (2011), pasó a ser la señal de una época donde la reconfiguración de $\mathrm{Eu}$ ropa como totalidad histórica reorganizó la hegemonía económica mundial, consolidando la modernización capitalista como única democracia posible. Este acontecimiento también significó el fin de los grandes relatos y consolidó el fenómeno de la posmodernidad, a la que Jameson (1992) también nombra capitalismo tardio.

Esta reorganización capitalista se presenta en América Latina como una restructuración de la noción de dependencia hacia una interdependencia asimétrica que, según Roberto Ayala (2004), se articula en la desnacionalización de las economías presentando entre 1990-1998 una fuerte inversión de capital extranjero, la persistente dependencia financiera donde las deudas no llegan a su fin y la dolarización a mayor escala que la ya oficializada por algunos países.

${ }^{5}$ La Teoría de la dependencia se consolida como un marco de análisis socio-político para América Latina. Es elaborada enlos años de 1950 y en las décadas posteriores, enriquecida por diversos teóricos, dentro de los cuales destacan Theotonio Dos Santos y Andre Gunder Frank. 
Mientras tanto, la posmodernidad proclama globalización, multiculturalismo y poscolonialidad. Lo latinoamericano es producción y producto del auge de los estudios latinoamericanos auspiciados por la academia norteamericana (Richard, 1997, p. 2) y a su vez reafirmado por los circuitos del arte internacional, donde la creación artística de la región tuvo como nunca antes una actividad de movilización y visualización a través de muestras generales -en su mayoría homogeneizantes- llevadas a cabo en las metrópolis (Ise, 2011, p. 39).

Las bienales también tuvieron un auge importante tanto dentro como fuera de la región que, si bien funcionan como medio de fortalecimiento de la producción artística regional, son también formas de internacionalización y mercantilización del arte, procurando la neutralidad hacia la anulación de significación. Como bien lo dice Traba "No hay que comprender sino "ver», no hay que totalizar sino fragmentar, no hay que pensar sino recibir, no hay que reflexionar sino aceptar." (2005, p. 69).

Para varios autores, los años de la década del noventa significaron un periodo de modificación de las relaciones de poder entre los centros y las periferias. Según Nelly Richard (1997, p. 10) la poscolonialidad ha permitido modificar esa dependencia de polaridad fija y homogénea hacia una dispersión estructural, descentralizando los centros y desplazando las periferias, aunque siempre articuladas según la cultura hegemónica, contribuyendo así con la permanencia de las desigualdades.
La globalización también predicó esta modificación, postulando en una de sus acepciones una sociedad global; sin embargo, en el 2000, esta categoría fue fuertemente criticada, acusada de ser una expansión capitalista inspirada en una ideología liberal extrema, creándose una postura de antiglobalización, que fue reforzada por la posición que asumió los Estados Unidos al proclamar su hegemonía mundial y su política de seguridad nacional contra el terrorismo, después de la caída de las Torres Gemelas. Esta postura, reafirmó el fracaso de la sociedad global, ante el miedo ideológico del otro - no estadounidense- que, en el trasfondo más allá de una posición nacionalista, resultó en la perpetuación de la lógica del capital.

\section{Áreas abiertas y áreas cerradas; Formas cambiantes}

Las estructuras sociales son cambiantes. $\mathrm{Si}$ bien pueden tener una constante por periodos, estas sufren transformaciones, y eso ha sucedido con las dinámicas de centro-periferia a través de gran parte de la historia humana. Ahora bien, esta categoría también puede ser aplicada para el estudio de las dinámicas a lo interno de las regiones o países. Ese es el caso del mapeo realizado por Traba basado en un esquema sistemático de dos categorías: áreas abiertas y áreas cerradas, las cuales tienen una estrecha relación respecto a cómo se presenta la cultura de la resistencia y la estética del deterioro en los circuitos del arte, tanto a lo interno de los países como a nivel regional. 


\section{Artículos}

La breve reflexión que a continuación expondremos sobre la creación artística de entre 1983-2003 en el contexto de Venezuela y Centroamérica, presenta interesantes diferencias con respecto a la lectura que realizó Traba en los años setentas, diferencias que sobresalen principalmente por el abordaje de épocas distintas que plantean otros desafíos para su comprensión. En este sentido, nos proponemos abordar estas categorías propuestas por Traba y analizar su empleo en la reflexión del periodo histórico escogido para este estudio.

Las áreas abiertas se caracterizan "[...] por su progresismo, su afán civilizatorio, su capacidad de absorber y recibir al extranjero, su amplitud de miras y su tendencia a la glorificación de las capitales." (Traba, 2005, p. 92). Para Traba, esta apertura a los modelos foráneos, específicamente europeos y norteamericanos, significaba la subordinación a la estética del deterioro, solapada en el deseo de asimilarse como igual. Argentina, Brasil, Uruguay, Chile, México y Venezuela son los países que Traba ubicó dentro de las áreas abiertas.

En el caso particular de Venezuela, el acelerado crecimiento económico entre las décadas del cuarenta y sesenta, generado por el petróleo, convirtió a su capital Caracas en una gran metrópoli. La efervescencia económica produjo cambios sociales y culturales: por un lado, desató la compra y posesión de arte, lo que significaba estatus social; por otro, fomentó la producción artística que, según Traba, estaba subyugada al afán de lo nuevo de la cultura dominante. Esta postura crítica sobre el camino que estaba tomando el arte venezolano llevó a la autora a sostener, en 1965, un intenso debate con críticos y artistas. Estas características del medio artístico y cultural venezolano fueron determinantes para que Traba designara a Venezuela como un área abierta.

El periodo de estabilidad económica del país llego a su fin en la década de 1980. El gobierno venezolano comenzó la implementación de medidas económicas para enfrentar la crisis financiera, adoptando políticas liberales que fomentaron la aplicación de reajustes estructurales que afectaron profundamente a la población, dando como resultado, en 1989, una gran ola de protestas, violencia y muerte, conocida como el Caracazo. Estos acontecimientos, sumados a varios aspectos que se abordan a continuación, son importantes para analizar la posible variable en la categorización de Traba, en que un área abierta puede transformarse en un área cerrada.

Para la crítica de arte Ruth Auerbach (1997), los acontecimientos de los años ochenta, tales como el Caracazo, debían ser detonantes de una reconfiguración en la creación artística, que estaba sumida en una representación vacía, carente de contenidos locales, un pastiche que continuaba supeditado a iconos del pasado, sumergiendo el arte de la década del ochenta en una crisis moral y ética.

Para la década de los noventa, el arte venezolano presenta una incorporación de 
nuevos lenguajes visuales, que para Nidia Tabarez representa un cambio en la percepción y conceptualización de las experiencias social-culturales de la época, ante lo cual "El artista utiliza con mayor libertad la diversidad de posibilidades expresivas, por lo que se despliega un abanico de modos de representación del entorno." (Tabarez, 2009, p. 105), lo que le permite atender el desorden social, cultural y ambiental que vive el país.

Este periodo estuvo marcado por dos golpes de estado en 1992, el evidente deterioro de la estructura social y el triunfo electoral en 1998 del teniente coronel Hugo Chávez Frías, que dio inicio a la República Bolivariana de Venezuela. Estos acontecimientos, en conjunto con los de las décadas pasadas, generaron en la creación artística diversas reacciones. Una de ellas fue la constante "llaga" de la identidad y de lo nacional que, para Auerbach (1997, p. 43), se reflejaba en la escaza consciencia respecto a las tradiciones históricas y populares.

Por el contrario, para Jenny Guerrero (2009, p. 151), lo nacional podía y había sido abordado por varios artistas a través de otros temas, como la representación de mitos urbanos y los movimientos sociales, para encarnar lo local. En este sentido, los problemas sociales vivenciados en la época, tales como la violencia, fueron tomados por varios artistas como temática para representar lo local -lo cotidiano de la realidad venezolana- elaborando un código general que fuera descifrado, reflexionado y criticado por el espectador.
En el año 2000, el interés por este tipo de reflexión continua presente y surgen varias iniciativas que promueven espacios de discusión y creación en conjunto a la experimentación de nuevos lenguajes, dentro de estas iniciativas encontramos proyectos de colectivos artísticos como Canal, La cuadra y Periférico Caracas (Morales, 2009, p. 305).

Continuemos este abordaje con la segunda categoría, áreas cerradas, definida por Traba como "[...] una categoría, donde predominan las condiciones endogámicas, la clausura, el peso de la tradición, la fuerza de un ambiente..." (2005, p. 92). A su vez, los países de esta área se caracterizan por tener una cultura que "[...] reposa sobre la triple alianza de la pobreza inmigratoria, la defensa de una tradición precolombina y colonial y la exaltación de valores locales." (Traba, 1972, p. 65). Perú, Ecuador, Paraguay, Bolivia, Colombia, la región de América Central y el Caribe, son las zonas que Traba catalogo como áreas cerradas.

Centroamérica es una región que si bien tiene evidentes especificidades marcadas por cada país que la integra, tiene, a su vez, muchas similitudes a causa de su historia. $\mathrm{Su}$ pasado colonial, la conformación de los estados-nación y la United Fruit Company son solo algunas. Dentro de estos vínculos, el más desafortunado y reciente es el de la guerra de la segunda mitad del siglo XX, encargada de convertir a la región en una de las más violentas en el mundo, acarreando consigo una serie de problemas sociales. 


\section{Artículos}

El arte no escapa de su momento histórico, y durante la década de 1970 y 1980 el trabajo artístico estuvo condicionado a las posiciones ideológicas enfrentadas en guerra. A su vez, fue este abatido por el fracaso de la Primera Bienal Centroamericana en Arte en 1971, en la cual la participación de Marta Traba como jurado fue muy controversial, principalmente por el desenlace de la premiación en que las menciones para Costa Rica, Honduras y El Salvador fueron declaradas como desiertas (Pérez Ratton, 2011).

En la década de 1990, después de los acuerdos de paz, Centroamérica experimenta una serie de cambios radicales en la creación artística que, para Virginia Pérez Ratton (2011), son resultado de los esfuerzos a nivel regional realizados desde años antes, con el objetivo de dar "visibilidad hacia fuera y valoración hacia adentro". Los espacios para el desarrollo del arte (auspiciados en su mayoría con inversión extranjera) se multiplicaron por toda la región -bienales, museos, seminarios, entre otros - permitiendo un renacimiento del arte centroamericano y dando lugar, en 1996, a la primera muestra de arte contemporáneo de la región titulada MESóTICA II: Centroamérica/re-generación.

Este periodo de transición en el arte es analizado por Pablo Hernández (2015) como "[...] un proceso de revisión de lo sensible y de la relación que lo sensible tiene con la vida social y con las formas culturales[...]". En este sentido, para Hernández, las sociedades sometidas a sistemas represivos están obligadas a reconsiderar sus límites y sus libertades. Así, para los artistas centroamericanos, el periodo después de los acuerdos de paz significó la apertura de esos límites, un espacio de experimentación de nuevas formas de expresión y creación.

Esta apertura y reflexión crítica es un aspecto interesante de relacionar con los años siguientes, por ejemplo, en el 2000, se llevó a cabo el primer seminario regional "sobre prácticas artísticas y posibilidades curatoriales" titulado Temas Centrales. En dicho seminario, se abordó la necesidad de plantear a Centroamérica como un centro que borra sus límites y expande sus posibilidades hacia la creación de un arte regional que represente su realidad y extirpe el estereotipo que le acecha (Pérez Ratton, 2011), reto colocado y discutido en aquel evento y que continúa vigente.

Las categorías de áreas abiertas y áreas cerradas no son constantes ni invariables; por el contrario, estas pueden modificarse según diversos factores que caractericen a las zonas en análisis, tal como se ha estudiado brevemente en el caso de Venezuela y Centroamérica. Lo interesante de estas categorías son las herramientas que pueden brindar, las cuales permiten analizar comparativa y críticamente las conexiones existentes entre el arte y la comunidad-país-región.

\section{Cuatro ejes vigentes}

A lo largo de este artículo se ha realizado una relectura de la obra de Marta Traba -específicamente la de los años setenta- a partir del 
abordaje de cuatro de sus ejes teóricos, con el fin de presentar la vigencia de este marco conceptual por medio de las reflexiones propuestas sobre el periodo entre 1983-2003.

Para finalizar, parece importante retomar la relación dialéctica que cada uno de los ejes expuestos presentan entre sí, es decir, están en una constante tensión y conexión, operan de forma cambiante y correlacionada. En este sentido, es posible ver la dinámica que se da entre la estética del deterioro y la cultura de la resistencia. Ambas categorías, en apariencia, son antagónicas, sin embargo, son necesarias la una a la otra para llegar a comprender el proceso en el cual operan.

En ese proceso participan en movimiento las categorías de centro-periferia y de áreas abiertas y áreas cerradas. La primera permite establecer un panorama amplio de las relaciones a nivel mundial comandadas por los centros hegemónicos, y la segunda funciona como una herramienta sistemática de análisis para estudiar esta injerencia de los centros hacia las periferias, tomando en cuenta las características propias de cada zona. Esto permite comprender las especificidades que cada área presenta en correlación con las otras, valorando sus dinámicas tanto a lo interno como a lo externo, dinamizando estas conexiones y evaluando las transformaciones que presentan.

Estas consideraciones se pueden visualizar en las reflexiones presentadas como, por ejemplo, la injerencia que tienen las condiciones económicas en la producción artística de los años de 1990, donde la interdependencia asimétrica coincide con la efervescente cantidad de exposiciones reduccionistas y normativas de lo que se considera arte latinoamericano en las metrópolis, y con el renacer del arte en Centroamérica en manos mayoritariamente de capital extranjero.

Dentro de los cuatro ejes abordados, el más emblemático es el de la cultura de la resistencia, el cual se puede pensar como uno de los mayores desafíos para el proceso creativo y la reflexión del arte contemporáneo, desafío que coloca como horizonte la capacidad de escudriñar la realidad y hacerla precisamente nuestra; que todos los sentidos estén dispuestos a percibir las provocaciones que día a día emite la vida misma y valerse de estas para crear algo que se inserte y articule en ella, es decir, que signifique. La resistencia viene a ser precisamente el resguardo de la existencia, no en lo que fue, sino en lo que es ahora en el presente.

Las posibilidades de reflexión crítica que brindan los cuatro ejes teóricos propuestos por Marta Traba son diversas y las aquí expuestas fueron solo algunas, las cuales permitieron comprobar que la teoría de esta autora proporciona la base para el desarrollo de un análisis -que tome en cuenta las partes y la totalidad- abordando el arte como una dimensión del proceso histórico-social, transfigurado y existente en el velo de las ideologías, en las crisis económicas, en las militancias políticas, en las resistencias culturales y en las formas de dominación del sistema social, que resultan en la miseria de 


\section{Artículos}

muchos y el éxito de pocos.

El estudio dialéctico del arte como un campo autónomo y, al mismo tiempo, como un hecho social, caracteriza el corpus teórico de Traba. Esta es una de las principales características que permiten que las posibilidades analíticas propuestas hace más de 40 años por esta autora tengan vigencia tanto en el estudio que se ha presentado como en la propuesta de otros análisis a ser desenvueltos. En este sentido, el legado de Marta Traba, para la teoría del arte en América Latina, no se encuentra delimitado a las obras que esta autora dejó, su legado radica en estudiar, analizar y criticar su obra paralelamente al abordaje de la dinámica del arte de nuestro tiempo y, con la misma pasión y dedicación que Traba mostró, continuar enriqueciendo el debate analítico y crítico del arte.

\section{Referencias}

Auerbach, R. (1997). La última contemporaneidad. La década de los 90 en el arte venezolano. Estilo, 80: 41-45.

Ayala Saavedra, R. (2004). América Latina: La restructuración de las relaciones de dependencia. Ciencias Sociales, I-II 103104: 115-126.

Echeverría, B. (2011). 1989. En Ensayos Políticos, Bolívar Echeverría, pp. 9098. Quito: Ministerio de Coordinación de la Política y Gobiernos Autónomos Descentralizados.

Guerrero T, J. (2009). La violencia como representación de "lo nacional" en el arte venezolano de la década de los 90. Presente y Pasado. Revista de Historia, 27: 145-160.

Hernández, P. (2015). Hacer cosas con palabras y con imágenes. La dimensión performativa del arte en Centroamérica. Gimnasia-Ejercicios contemporáneos. Recuperado de http://revistagimnasia. com/entradas/2015/3/10/hacer-cosas-con-palabras-y-con-imgenes-la-dimensin-performativa-del-arte-en-centroamrica? rq=pablo $\% 20$ hern\%C3\%A1ndez

Ise, M. L. (2011). Arte Latinoamericano en los ochenta y noventa: Una mirada desde algunas exhibiciones y catálogos. Nómadas 35: 30-47.

Jameson, F. (1992). Postmodernism, or, the cultural logic of late capitalism. New York: Verso.

Morales, E. (2009). La disidencia en Venezuela. Una perspectiva histórica. Presente y Pasado. Revista de Historia 28: 305-318.

Mosquera, G. (2003). Del arte Latinoamericano al arte desde América Latina. ArtNexus 48: 70-74.

Pérez Ratton, V. (2011). ¿Qué región? Apuntando hacia un estrecho dudoso. Istmo, 22. Recuperado de http://istmo.denison. edu/n22/articulos/14.html

Richard, N. (1997). Mediaciones y tránsitos académico-disciplinarios de los signos culturales entre Latinoamérica y el Latinoamericanismo. Dispositio, 22 (49): 1-12. 


\section{Artículos}

Tabarez Reyes, N. (2009). Esbozo histórico del arte de representación de paisajes en Venezuela desde principios hasta finales del siglo XX. Tiempo y espacio 51: 89-110.

Traba, M. (1970). El éxito de los derrotados. Revista del Instituto de Cultura Puertorriqueña 47: 8-11.

. (1972). Arte Latinoamericano actual. Caracas: Ediciones de la Biblioteca de la Universidad Central de Venezuela.

- (1973). La pintura como medio de comunicación. Revista de la Facultad de Humanidades Universidad de Puerto Rico, 2: 195-203.
- (1979). Artes plásticas latinoamericanas: La tradición de lo nacional. Hispamérica, 23 y 24: 43-69. . (1994). Arte de América Latina: 19001980. Washington D.C.: Banco Interamericano de Desarrollo.

. (2005). Dos décadas vulnerables en las artes plásticas latinoamericanas, 19501970. Buenos Aires, Argentina: Siglo XXI. . (2009). La cultura de la resistencia. Revista de Estudios Sociales (34), 136-145. 
Artículos

102 ESCENA. Revista de las artes, 2016, Volumen 76, Número 1, págs. 85-102 ISSN 1409-2522 